Article

\title{
Aggregated Roles of Smartphones in Young Adults' Leisure and Well-Being: A Diary Study
}

\author{
Anna Irimiás ${ }^{1, *}$, Tamás Csordás ${ }^{1}$, Kornélia Kiss $^{1}{ }^{\mathbb{D}}$ and Gábor Michalkó ${ }^{1,2}$ \\ 1 Institute of Marketing, Corvinus University of Budapest, 1093 Budapest, Hungary; \\ tamas.csordas@uni-corvinus.hu (T.C.); kornelia.kiss@uni-corvinus.hu (K.K.); \\ gabor.michalko@uni-corvinus.hu (G.M.) \\ 2 Geographical Institute, CSFK, 1112 Budapest, Hungary \\ * Correspondence: anna.irimias@uni-corvinus.hu
}

Citation: Irimiás, A.; Csordás, $\mathrm{T}$. Kiss, K.; Michalkó, G. Aggregated Roles of Smartphones in Young Adults' Leisure and Well-Being: A Diary Study. Sustainability 2021, 13, 4133. https://doi.org/10.3390/ su13084133

Academic Editor: Carlos Salavera

Received: 12 March 2021

Accepted: 6 April 2021

Published: 8 April 2021

Publisher's Note: MDPI stays neutral with regard to jurisdictional claims in published maps and institutional affiliations.

Copyright: (C) 2021 by the authors Licensee MDPI, Basel, Switzerland. This article is an open access article distributed under the terms and conditions of the Creative Commons Attribution (CC BY) license (https:// creativecommons.org/licenses/by/ $4.0 /)$.

\begin{abstract}
Young adults spend most of their leisure time in the company of their smartphones. Drawing on the theory of digital well-being and on the concept of psychological sustainability, our aim is to investigate the relationship between digitalization-dominated leisure-time consumption to identify the aggregated roles of smartphones. We suggest that smartphones play different roles in young adults' daily life. To test our predictions, we used a qualitative method, a two-day time-use diary with structured interviews; two sample groups were recruited for data gathering. The results of the content analysis and of the qualitative sentiment analysis show that mobile devices have a marked agenda-setter function, along with the functions of 'separator' and 'enabler'. The use of smartphones leads to idleness and perceived timelessness while staying physically immobile. Results expand our knowledge on the aggregated role of smartphones in young adults' activities. Wider society can benefit from the research findings, stimulating young adults to acknowledge the aggregated roles and functions of their smartphones and to develop their digital well-being.
\end{abstract}

Keywords: leisure time; smartphone; diary study; qualitative method; well-being; young adults

\section{Introduction}

Alarm clock, news, greetings, schedule, meetings, weather forecast, shopping: the list of smartphone uses could go on. What roles do smartphones exactly play in young adults' leisure-time activities? It is evident that smartphone use is constantly shaping leisure consumption behavior [1] and, consequently, quality of life [2]. Research has shown that young adults' leisure practices, experiences and forms are mostly digitalized and often displayed on digital platforms [3]. Physical activities such as sports are monitored by wearable devices in order to self-track and share achievements with audiences on social media platforms [4]. Playing games, watching/creating videos, and checking social network sites dominate the leisure time activities of many [5]. The reading habits of young adults have turned digital: fashion, travel, and entertainment magazines are mostly read on mobile devices [6]. It is commonplace by now to say that information and communication technology (ICT) is present in every part of human life with its advantages and disadvantages [3,7]. The advantages brought about by smartphones, such as time and communication efficiency, the immediate availability of information, the possibility of information sharing, etc., are undeniable [8]. Recent research [9] shows that the recreational use of virtual realities, among others, helps to improve the well-being of young adults while under lockdown. At the same time, the many disadvantages related to one of the unwanted effects of digitalization, namely ubiquity and the subsequent continuous online presence can now also be experienced on both individual and social levels $[10,11]$. Social scientists, medical psychologists, and ecologists alike have been drawing attention to the negative effects of causes clearly linked to humanity moving away from the natural environment 
and to an accelerated, digitalized, and virtual lifestyle on one's quality of life (such as sleep disorders, acute stress, attention deficit) [1,3,12].

Spatial and temporal boundaries have become liquid; the concepts of worktime and leisure time have become increasingly difficult to grasp, social relations and interactions have gained new meanings, while the dynamics of social involvement and leisure activities have also become ever more multidimensional, taking place in physical, virtual, and perceived spaces [13]. Leisure time consumption is influenced by a myriad of factors from demographic, sociographic, psychological, to attitudinal factors, as Kökény and Kiss [14] evidenced in their recent study.

The study of the effects and contexts of digitalization and interconnectivity has therefore become a necessity in the field of leisure with a focus on digital well-being [15]. The available literature is very rich, but at the same time diverse. The present study is positioned in leisure studies [12,16] and draws on the theory of digital well-being [15] suggesting that hedonic and eudemonic experiences are not only significant but also functional in young adults' life. Moreover, acknowledging that a healthy balance is needed to manage online and offline leisure activities, we employ the concept of digital well-being [15]. The central proposition of this paper is that leisure-time consumption with a smartphone as a full-fledged companion influences subjective well-being, moods, and feelings related to activities during daytime. As such, understanding the roles a smartphone plays in young adults' lives can provide new insights into leisure time consumption. The present paper aims to improve upon prior methodological approaches [10] to assess digitized leisure consumption with solicited diary research and inviting participants to reflect on their own diary-keeping and the roles they give to their smartphones.

In the present study, we examine the demand side, and therefore study the latest literature in the cross-section of studies on smartphone use [5], leisure [4], and well-being [2]. Our research question seeks to investigate the relationship between leisure dominated by digital technologies and well-being, employing an experimental qualitative method such as the solicited written daily diary. The present research enriches literature on leisure-time consumption and on the aggregated role of smartphones in young adults' activities through the investigation of how individuals negotiate their everyday life.

\section{Theoretical Background}

\subsection{Smartphones, Hybrid Spaces and Leisure}

Ubiquity and convergence are two prominent features of current mobile communication technologies, that is, the availability of a device that fits in a pocket that has a number of applications that help everyday life [17]. According to Klopfer and Squire [18], smartphones have become a determining, if not norm-setting [19] phenomenon of the digital era thanks to the ability to bring together the following characteristics: portability, social interactivity, context sensitivity, connectivity, and individuality. Moreover, mobility brings about a unique and novel consumption setting as a result of which the smartphone has become the first location-specific mass medium (i.e., locative media) [20]: the consumption of digital content has shifted from a fixed space to the consumer's everyday physical environment, thereby making the digital content consumer present simultaneously in the physical and digital spaces, leading to a close interaction between the two dimensions. What is more, consumers located in different places can be connected by mobile technology to be together, while consumers located at the same physical space may have significantly diverse perceptions and interpretations of that space, which leads to the phenomenon of the multiplicity of space [21]. Through this integration of digital technologies to the physical space, the smartphone act as a "Swiss army knife" [22] and provides consumers with an augmented possibility of immediate problem solving, and information and need satisfaction [16]. Being "offline" nowadays is almost reduced to being asleep. 


\subsection{The Hybrid Space as a Playground}

Mobile technology also has a deep impact on consumers' leisure time: the consumer becomes available even in their free time, and the entertainment and time-filling function of the technology equally gains importance. The hybrid space [9,23], forged by the transition between physical and digital environments, provides an excellent basis for the application of gamification through which a service provider may use playful elements and rewards in non-playful environments to encourage users to behave in certain ways, e.g., to interact with the brand [24], thereby deepening the user experience of a service or the involvement of consumers [25]. Another paradoxical feature of mobile media is that despite its status of mass medium based upon its high reach and time spent, it is, at the same time, the most personal and most personalizable device and environment for content consumption, where the consumer has a more extensive control over their own access to the consumption, production, and sharing of content than with any other medium [26]. Moreover, high device penetration entails that each device is linked to a person, and therefore is infinitely personal, while its owner is practically always within reach.

\subsection{Dangers of the Hybrid Space}

The personal nature and assimilation into everyday life of smartphones bring about a number of dangers on the individual level. First and foremost, is the formation of addiction. Bae [1] confirms the positive relationship between information search, entertainmentseeking, gaming, fear of missing out, and smartphone dependence. The latter can lead to undesirable outcomes such as concentration and behavioral disorders (e.g., deliberate use in dangerous or prohibited situations (see, e.g., deaths related to taking selfies, [27]), loss of attention to the physical world (e.g., in traffic situations), deteriorating social skills, anxiety, depression, etc. [28]). Another peculiarity related to the new consumption setting is the "pulsating" nature thereof; that is, each individual content consumption session is likely to be short in time, while the frequency of use during the day is higher, almost compulsive (cf. nomophobia, or no-mobile-phobia, the anxiety caused by not having a working mobile phone at hand). It is also important to note that content consumption on smartphones is often not an exclusive activity, and the user's attention in the hybrid space is in most cases divided between the screen and the perception of physical reality as described by the phenomena of multitasking, and even technoference (or phubbing) such as the interference of technology in relationships [29], which in turn might lead, in the worst case, to a fragmentation of one's attention (see, e.g., [30]) and a deterioration in the quality of lived experiences and human connections (see, e.g., [31]).

As in most studies related to leisure, labor is often mentioned in studies about smartphone use during leisure [10,11,32]. According to Agger [33], the internet introduces an extra dimension of time referred to as "iTime" where the boundaries between labor, social, and private lives, between labor and free time, day and night, and between space and time are blurred. The notion of detachment refers to a state of mind where an individual feels removed from their work both physically and mentally [34]. In her study on the separation of work and personal life, Mellner [32] found that high expectations to be available for work-related inquiries outside regular work hours, work-related smartphone use during off-work hours, and inadequately separated worktime and leisure time lead to insufficient levels of psychological detachment. Derks and Bakker [10] note that a frequent use of smartphones directly contributes to blurring the sharp line between work and leisure times. The authors point out that smartphone use severely hinders the critical process of recovery, especially when there is a high perceived level of work-home conflict [9-11].

\subsection{Digital Well-Being}

Well-being is a popular area of interest for theoretical and applied research. In the last few decades, research has been conducted in various areas of science: primarily psychology [35,36], sociology [37], economics [38], and leisure [2]. Gui et al. [39], starting from the concepts of digital overconsumption and digital multitasking and from the recog- 
nition of the influence of digitalization on general well-being, both in its hedonic and eudaimonic dimension, define digital well-being as "a state where subjective well-being is maintained in an environment characterized by digital communication overabundance" (p. 166). Verduyn et al. [40], focusing on the relationship between social network sites and subjective well-being, explain how these constructs are related to the active usage of social network sites. Drawing on prior studies, here, we adapt the definition coined by Vanden Abeele [15], who conceptualizes digital well-being as "a subjective individual experience of optimal balance between the benefits and drawbacks obtained from mobile connectivity" (p. 7).

Schwanen and Wang [41] explored the role, characteristics, and main domains of wellbeing in the digital era. Theories that capture the quality of life and subjective well-being, and the perception of living a 'good life' focus on the individual's perception of life/idea of a good life. Thus, we draw upon prior studies [36] to approach the cognitive and affective dimensions of well-being and young adults' leisure experiences. Veenhoven [36] argues that life evaluation is a general picture based on two pillars: comparing our lives to the attributes of the "good life" (satisfaction) and how we feel most of the time in general (hedonic feelings). According to Kjell [42], hedonic happiness plays an important role in the research of subjective well-being. In his view, life satisfaction and high values of positive emotions, when coupled with low values of negative emotions, mean a high degree of well-being. Similarly, in Diener's [35] definition, subjective well-being includes both cognitive and affective elements, and can be divided into three components: pleasant or unpleasant emotions, and overall life satisfaction. Although much has been written on emotions, definitions differ across disciplinary boundaries. Based on Ashforth and Humphrey [43], here, 'emotion' is defined as a subjective feeling state which involves physical reactions (heart rate) and explicit behavior (increased use). 'Life satisfaction' stems from an assessment of the factors that represent the circumstances of life and is characterized by a sense of awareness. Ryan and Deci [44] distinguish between two types of subjective well-being: eudemonic and hedonic happiness. Eudemonic happiness indicates the joy of engaging in activities, while hedonic happiness indicates positive emotions in meeting our needs. The study by Dolan et al. [38] gives an overview on the various domains of well-being. Based on the sampled large-scale studies, the authors identify 'how we spend our time' as one of the seven domains (income, personal characteristics, socially developed characteristics, attitudes and beliefs towards self/others/life, relationships, and the wider economic, social and political environment) that potentially influence well-being. Most importantly for the present study, how young adults spend their leisure time is particularly relevant considering the digitization of leisure activities $[1,3]$.

\section{Methods}

In order to collect information on how individuals negotiate their everyday life and consume their leisure time, an experimental qualitative method was employed. We assessed the relationships between daily time spent in leisure activities, and work/study obligations with self-report data. The 'researcher-driven diary' approach [45] was deemed suitable for data collection because it allowed real time assessment on participants' experiences and behavior [46]. When individuals are asked to take notes about their momentary experience, they do not have to recall memories, thus minimizing cognitive biases such as recalling 'general' experiential cues or using stereotypes. These real-life conditions are optimal for the assessment of experiences during leisure time, thus justifying the use of the diary method. This method is often referred to as structured observation because the diarist observes with attention to their behavior and momentaneous feelings and moods [45,46].

Data instrument: a time-use electronic diary in the form of an Excel file was designed by the researchers and was shared with participants. The diary was in Hungarian and was divided into 15-min intervals; diarists were asked to indicate for each interval details of their activities, and the mood or feelings experienced during activities. Participants were asked to take notes on a chosen weekday and day of the weekend. No word limit was set, 
but diarists were asked to write at least 150 characters for each activity to assure sufficient depth. Time dedicated to sleeping was indicated as rest and left blank. Once the diaries were completed, participants had to answer three open-ended questions reflecting on the positive and negative effects of smartphones on their leisure-time consumption.

Data collection: data collection was carried out in November to December 2020, close to the end of the first semester. In the first step, participants were asked to complete the diary and to record, more or less contemporaneously, the amount of time engaged in activities and smartphone use. This 'experience sampling' was particularly suitable to observe participants' behavior in a natural setting. In the second step, we used open-ended questions on the evaluation of how leisure consumption influenced diarists' subjective well-being, and opinion on their digital well-being and psychological sustainability. As recommended by Zimmerman and Wieder [47], this method is complementary to the diary when diarists not only indicate the timeslot of different activities but describe their behavior and feelings in prose. To assure reliability, the diary was thoroughly tested in a two-wave pilot study ( $n=5$ students each) before the final delineation of the activities and feelings to record. Wording of the instructions was modified where needed. Finally, the time-use diary along with a protocol for diarists was delineated with explicit instructions on what was required and when the kinds of activities and moods should be focused. This allowed to mitigate the risks emerging from the coding of free-text entries.

Sample: the convenience sample method was used; participants were recruited in the framework of three different BA-level university courses at Corvinus University of Budapest (Hungary) such as Introduction to Marketing Communications, Media Vehicles and Advertising, and Leisure and Tourism. Respondents were undergraduate business students with various majors (a majority in commerce and marketing and hospitality and tourism). The final sample resulted in 57 participants (48 female, nine male participants; $M_{\text {age }}=22.3$ ). It is acknowledged that female respondents are overrepresented; according to Babbie [48], it is an inevitable in all surveys because females are more willing to participate in research. In the investigated segment of university students, females are overrepresented in general, so is not at all surprising that in the research sample the ratio of the females is higher. Bias in sampling was minimized by setting a control variable, dividing participants into two groups. Sample A: prior to completing the time-use diary, $n=29$ participants watched a short video (2.5 min long) in class. The video was filmed by a female student who recorded herself during a weekday. On the video: in the Leisure and Tourism course, prior to the diary research, students were asked to represent their leisure activities either in textual or visual form. One of the students shot a short video with her smartphone on her leisure time and registered her activities with particular attention on leisure activities, smartphone use, and the screen time dedicated to social media. The video shows that she is inseparable from her smartphone and how social media networks absorb her full attention. In her leisure time, she is constantly checking her smartphone, even while she is driving, walking the dog, or having dinner with friends. At the end of the video, as a "moment of truth," data of her screen-time use is shown: $9 \mathrm{~h} 1 \mathrm{~min}$ on an average day. The video had background music but no narration, thus allowing viewers to form an opinion without the video-maker's influence. An in-class conversation was held on the topic of spending free time and its impacts on subjective well-being. Sample B: participants $(n=28)$ did not receive any prior stimuli before the diary completion.

During data cleansing, all identifiable personal data was removed from the sample by one of the authors. Each respondent was randomly assigned an identifier ("\#01" to "\#57") which also served to link their responses in the two databases (diaries, open-ended questions). The coders relied exclusively upon this anonymized document in their analysis of the data.

Data analysis: qualitative content analysis and sentiment analysis were employed to assess data. The various activities were grouped into categories (pre-coding stage) in the researcher-driven diary: activities perceived as duty and perceived as non-duty. Once the diaries were collected, we created a merged database and a 136-page cleansed transcript 
for further content analysis. Since time-use diaries can be considered as structured observations, manual coding was preferred for data analysis [49]; no specific software was used to assess the data. The coding was conducted separately by the authors. Following Strauss and Corbin's [49] recommendations, the coding process was conducted in three distinctive steps: (1) open coding, (2) axial coding, and (3) selective coding. First, the transcripts of the merged diaries were read several times to identify themes and categories. The authors coded the transcripts line-by-line for meanings during analysis. In this interpretive process of open coding, data were broken down analytically and emerging topics were labelled (e.g., the frequent joint recurrences of smartphone use and being laid down before going to sleep or after waking up led to a code dubbed "[mobile as] sleep regulator"). In this phase, coders equally noted down specific comments and observations to be further discussed with their peers. Next, in a data reduction process [49], initial codes were grouped together. After an initial and detailed discussion between coders, overlapping categories were eliminated and a revised coding frame was developed. The transcripts were then reread and recoded in light of the new structure during axial coding (e.g., the above-mentioned "sleep regulator" code was integrated under a wider and more meaningful code dubbed "[mobile as] agenda setter"). Finally, patterns thus identified were used to develop the final categories that served as a basis for the analytical dimensions investigated in the following section and led to the development of our empirical framework.

Research ethics: All subjects gave their informed consent for inclusion before they participated in the study. The study was conducted in accordance with the Declaration of Helsinki, and the protocol was approved by the Ethics Committee of the Corvinus University of Budapest (Hungary) (Project identification code: KRH/103/2021).

\section{Findings}

One of the main results of the present study pertains to the importance of digital devices as regards sleep time and recreation. To note that, our findings are based on an exploratory investigation of a convenience sample. Our chief aim was to understand (as opposed to generalize) the role of smartphones in respondents' everyday dealings. Thus, our results are not representative of the total population.

All in all, the bed turned out to be by far the most often mentioned physical location in our sample in connection with mobile device use. More precisely, almost all of our respondents mentioned actively using their smartphones directly before going to sleep and/or after waking up, thereby becoming an integral part of their related end-of-day and/or beginning-of-day routines. Beyond the well-studied problem of screen consumption on sleep quality (see, e.g., [50]), and sleep time (using digital devices instead of resting and/or as an alarm clock and therefore artificially breaking one's sleep cycle-i.e., deprivation), our findings reveal an aspect on physical activity: namely, that the physically most passive part of one's day is sometimes considerably elongated, thereby contributing to respondents' increased idleness (i.e., "cocooning"). An extreme case of cocooning turned out to be one respondent, who, after waking up, had not left their bed for their first work-related activity (here: participating at a virtual university class), followed by another session of recreational mobile use, and only then leaving the comfort of their bed.

Based on the comprehensive reading of our sample, an interesting paradox surfaced related to the connectedness of mobile devices. While these devices offered a perceived virtual connectedness to respondents, they often also seemed to establish an actual disconnection between parts of the day, effectively acting as separators in between activities. These physical separators, in the descriptions of our respondents, were related to daytime breaks - pauses, which, again, can be related to the idea of rest. This way, based on the diaries, respondents' days can be conceptualized as a set of steps (activities), all of which have an identifiable connection to a specific use of mobile devices.

Active screen consumption during the physical inactivity phases was found to play three distinct roles in the sample. The first turned out to be external interest towards the activities of one's social connections (fear of missing out, FOMO). The form of reassurance 
manifested in our sample is in line with what can be referred to as a new form of FOMO, that is, "missing out on what would have been in a world not utterly altered" by the pandemic situation [51]. In other words, by acknowledging that all of one's social connections remain in a comparable situation (not being able to make up for involuntarily missed opportunities themselves), a sustained mobile social media consumption becomes a tool for self-justification and reassurance. This reassurance pertained in the descriptions to, once again, ideas of idleness and isolation (cocooning).

In connection with this latter dimension, using the mobile device as company was equally a recurring topic. Not only the connected device-through social media-offers a connection to people in the outside world, but it itself becomes a companion to hide and/or counter one's solitude. For instance, in typical moments of solitude (e.g., public transportation, house cleaning) media use (e.g., listening to music) through the mobile was quasi-omnipresent in the sample. On the contrary, when actual company was mentioned as being present, a conscious avoidance of mobile device use was also often reported in the diaries. Respondents equally often noted browsing on their phones with no apparent goal, simply out of habit, which raises the idea of compulsion. Combined with the fact that these pauses were often referred to as self-awarded rewards (e.g., for a chunk of work done), the notion of addiction arises.

This is even more reinforced with the third identified role of mobile devices which can be characterized as a more or less unconscious activity whereby a number of the most blatant self-contradictions in the sample could be observed. By artificially dividing the day into chunks, the concept of time itself is altered by the use of connected devices. The aforementioned ideas of (un)conscious phone use (technological unconsciousness [15]) also bring about the larger concept of immersion. Time becomes a fluid concept, and the respondent is floating in a timeless plane. The aforementioned pauses break them out of their physical time cues and render them into a virtual plane with a perceived timelessness (Table 1).

A more overall positive function for mobile devices was equally identifiable in the sample, albeit a lot more discreetly than expected from the previous literature on their ubiquity [10]. Mobile phones did also indeed appear as enablers in daily prompt tasks, such as looking for recipes directly before cooking or looking for Christmas present ideas before going shopping. In a more sustained context, mobile media consumption was reported to contribute to respondents' long-term and sustainable leisure activities, such as hobbies, by offering inspiration and/or self-development through educational videos (e.g., do-it-yourself videos, training/fitness videos, cooking videos).

In line with Diener [35], Veenhoven [36], and Vandel Abeele's theory [15] of well-being, in the second phase of our research, we examined how satisfied respondents were with their time use and what positive and negative feelings they had about smartphone use during their leisure time. Reflecting upon their own diaries, many respondents declared having spent their time well. The number of those respondents being more or less satisfied or dissatisfied $(n=22)$ with their time use was considerably lower than that of those completely satisfied $(n=37)$. According to an analysis of the responses of the latter, a sense of purpose, mindful planning of the day, and an evaluation of the completed tasks at the end of day are the most important factors that contribute to filling respondents with positive feelings.

Interestingly, the smartphone appears more prominently in the responses of the dissatisfied respondents, a dissatisfaction with their time spent with their mobile being a recurrent remark (Table 2). Due to the timing of our sampling, it was unsurprising that the pandemic has appeared in the answers. However, a few respondents went as far as using the extraordinary situation as an excuse, or even more, as a redemption (Table 2) for spending that much time with activities with lesser perceived added value. The number of mentions of meaningful activities was negligible in the sample. 
Table 1. Illustrative quotes-Diaries.

\begin{tabular}{|c|c|}
\hline Dimension & Quote \\
\hline "deprivation" & $\begin{array}{l}\text { "After waking up, I alternated between being hung on my phone and trying to rest; [ . . . ] it would } \\
\text { have been enough for me to wake up [later]; I was still tired, but didn't manage to fall asleep." (\#02) }\end{array}$ \\
\hline "cocooning" & $\begin{array}{l}\text { "I woke up. Usually, unfortunately, my first thing is to look at the news, my social media pages. I } \\
\text { always wonder what happened while I slept." (\#01) } \\
\text { "I'm already in bed. At such times, unfortunately, I almost always reach for my phone" (\#20) }\end{array}$ \\
\hline "separator"| "FOMO" & $\begin{array}{l}\text { "I was reassured to find that I haven't missed out on anything; but [using my mobile] was totally } \\
\text { adequate for relaxation" (\#42) } \\
\text { "I was browsing through my mobile; I checked on social media to see what had happened [ ... ] to see } \\
\text { what the others do." (\#06) }\end{array}$ \\
\hline "separator"| "company" & $\begin{array}{l}\text { "I was glad I could watch YouTube [while eating], because I didn't feel alone that way" (\#29) } \\
\text { "I tend to listen to music or podcasts [on my phone] while cooking, but today [exceptionally] I had } \\
\text { company, so I didn't need to do that." (\#12) } \\
\text { "Lunch with the near family. These [...] happen quite rarely; [...] the time passes with conversations. } \\
\text { I didn't use my phone" (\#03) }\end{array}$ \\
\hline "separator"| "(un)consciousness" & $\begin{array}{l}\text { "All of the family was together; we had dinner and talked. At these occasions, I try not to be hung on } \\
\text { my phone, but sometimes it's hard because I sometimes get an important message." (\#12) } \\
\text { "In the meantime, I didn't use my phone actively, but I replied to a message, for example" (\#29) } \\
\text { "I was browsing through the internet a little"; "I kept on scrolling through social media" }\end{array}$ \\
\hline $\begin{array}{l}\text { "separator"| } \\
\text { "self-reward" }\end{array}$ & $\begin{array}{l}\text { "I was pleasantly tired of learning, [so] I ran through a few news pages on my phone, but didn't use } \\
\text { it for long" (\#03) } \\
\text { "Phone pause from studying. [ ... ] after concentrating on learning for a longer time, I take my } \\
\text { phone into my hands and look around my Instagram; I didn't have time to watch it in full during the } \\
\text { morning, but I remained curious" (\#07) } \\
\text { "A little break from learning, mostly watching videos on YouTube [...]. Returning to learning [...] I } \\
\text { tried to get deep into learning again, but I had a bit of a hard time bouncing back." (\#08) }\end{array}$ \\
\hline "timelessness" & $\begin{array}{l}\text { "this was followed by watching YouTube videos, I spent a lot of time with it, I'm a little ashamed of } \\
\text { myself sometimes that I get so lost in it." (\#45) } \\
\text { "I was browsing on Instagram. I think this time is a bit wasted, even though it was relaxing" (\#46) } \\
\text { "I still felt like I wasn't rested enough, so I spent more time on the phone. At the time, I felt that I } \\
\text { needed it, but at the end of the day, I usually realize that it's not healthy to watch the screen in my } \\
\text { spare time and also for my duties (being in online education)." (\#53) } \\
\text { "Watching YouTube videos. I tried watching less Netflix lately, [...] but it wouldn't really matter } \\
\text { because I spend a lot of time with [YouTube], too" (\#57) }\end{array}$ \\
\hline
\end{tabular}

Note: authors' translation. Emphases added by the authors. Source: own research sample.

Positive and negative feelings about smartphone use were investigated through three open-ended questions. The first question was about the effects of smartphone use on the respondent in general, the aim of the second one was to identify the positive effects/feelings, and the purpose of the third one was to identify the negative effects/feelings. Respondents used terms such as "struggle" (against smartphone use) or "addiction" in their responses when expressing their negative feelings, while some of them suggested that they could have done something else than wasting time with their smartphone, thereby consciously recognizing that not all time spent using digital devices is spent valuably (Table 2).

Positive mentions of mobile use pertained predominantly to the mobile as a means of keeping in touch with friends and family, thereby reinforcing the enabler function identified in the analysis of the diaries [43].

A relatively larger number of respondents declared not being affected by smartphone use. The pros and cons, the positive and the negative feelings regarding smartphone use, are shown in Figure 1. The most common benefits mentioned were keeping in touch with family and friends, along with the aforementioned enabler function in a variety of areas. The disadvantages can be grouped into a few well-defined clusters, the expressions that most often appeared in this relation were either related to time spent with the device ("too much time", "no sense of time", "waste of time") and to the vanity of the activity ("useless", 
"unnecessary"), along with the "addictive" feature surfacing once again. The idea of addiction here is reinforced by respondents often mentioning the specific recreational activities sacrificed to the use of the device (such as talking to family or friends, doing sports, or doing some creative activity), while the use itself is often described as motoric and less conscious (e.g., "scrolling the screen"). The mentioned "symptoms" of addiction were terms such as "distracting attention", "stressful", or "annoying", as shown in the word clouds based on the data in Figure 1.

Table 2. Illustrative quotes-Respondent self-reflections.

\begin{tabular}{ll}
\hline \multicolumn{1}{c}{ Dimension } & \multicolumn{1}{c}{ Quote } \\
\hline "enabler" & "My smartphone is useful because I can handle a lot of duties and get access to any information. \\
However, I am often so absorbed by my screen that I don't notice what's really going on around me in the \\
real world. I have ambivalent feelings about my smartphone, but I find it mostly helpful and it makes a \\
meaningful contribution to my life." (\#28) \\
"It's easy to forget about the surrounding world while using your smartphone. This can have a (negative) \\
effect on my pre-planned agenda. It also takes valuable minutes when I forget to live real events because I \\
have my phone in my hand." (\#14) \\
"Using my smartphone in my leisure time is partly positive, partly negative. I think you can use your \\
smartphone for many useful things, which I am used to. However, I think I'm somewhat addicted to it \\
and it's almost always an active part of my free time, which isn't necessarily positive." (\#06) \\
"My smartphone has a lot of apps that are useless and absorb a lot of time out of my life. I scroll social \\
media platforms very often, which is also waste of time. These are the ones that I think are the main \\
negative effects and which make you a little addicted by influencing your free time. (\#12) \\
Not pathologically, but my smartphone made me addicted. When I think about what I usually do in my \\
leisure time and think that I always have my phone with me during these activities, it's just crazy. \\
Anytime I reply to a message, a notification, or and event, it was like I had a conceited beep on my phone. \\
Thinking about these episodes, it's like my smartphone limits my free time." (\#52)
\end{tabular}

Note: authors' translation. Emphases added by the authors. Source: own research sample.
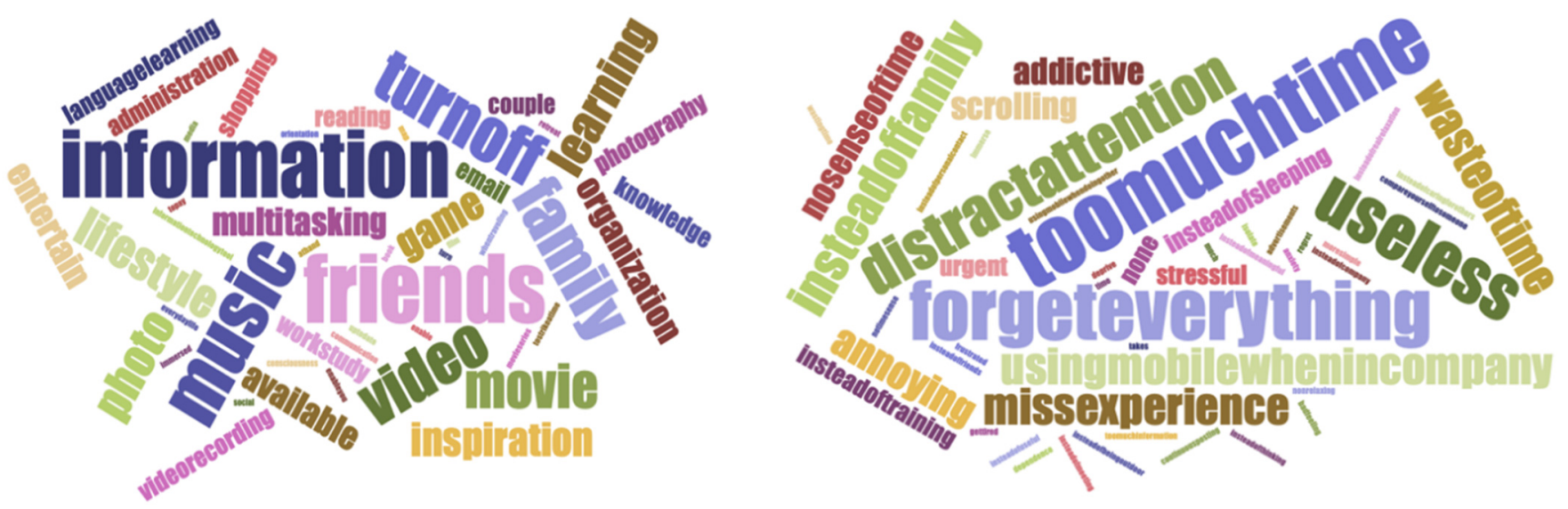

Figure 1. Smartphone as an enabler and as an addictive device in the sample.

All off the above lead to the conclusion that mobile devices have a marked agendasetter function in the lives of our respondents. The day starts and ends with the device and it is divided around it. The identified perceived timelessness in the diaries and conscious tension therefrom in respondents' self-evaluations confirms the conflicting role of the device.

On the technological side, their ubiquity is commonplace, and such was their presence in the diaries. However, on the human side, insecurity prevailed: the diaries suggested contradictions between respondents' actions and thoughts, while the subsequent selfreflections showed a level of verbalization of doubt and were inconclusive as to whether 
mobile devices are perceived as harmful or useful by them. Figure 2 gives a structured overview of our study detailing the main identified roles of mobile devices in connection to respondents' daytime activities as well as the respective deduced positive and negative effects on sustained psychological well-being.
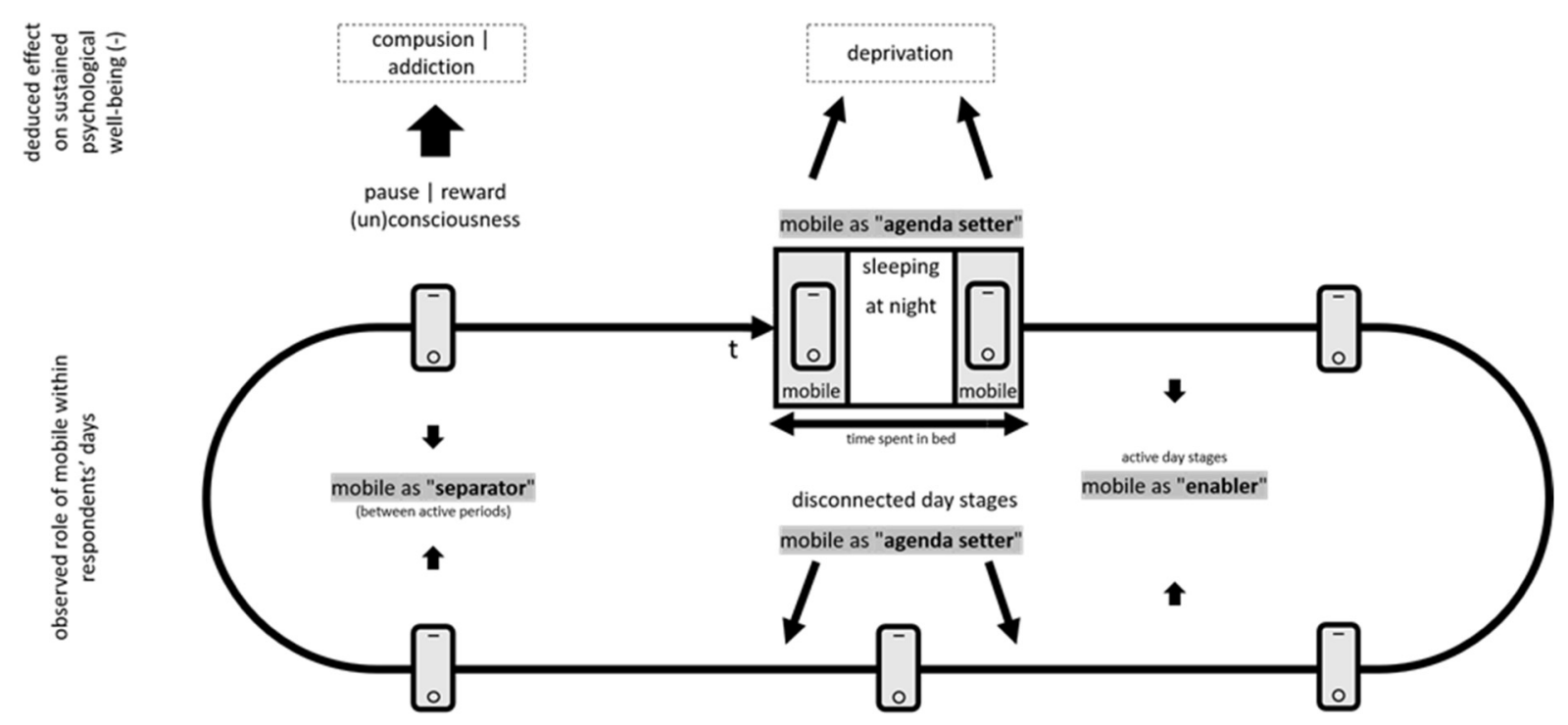

Figure 2. Aggregated role of the smartphone in respondents' activities.

\section{Discussion and Conclusions}

The study aimed to investigate the different roles played by smartphones in young adults' leisure time consumption and well-being. Using a qualitative research method and stimulating participants to reflect on their own experiences and feelings related to their leisure time consumptions, we found that smartphones are not only the digital extensions of young adults' bodies but are perceived as companions, enablers or separators. Our results confirm the findings of past studies $[5,7,8,11,12]$, revealing that young adults' leisure time activities, experiences and forms are digitized and experienced in hybrid spaces [23]. In the theoretical background, we mentioned that being "offline" nowadays is almost reduced to being asleep. Our findings indicate that even this is only partly true, as the quantity of sleep an individual receives and the structure thereof are equally heavily affected by smartphone use.

Based on our findings, we extend the concept of digital well-being introduce the importance of place. The bed, as a physical and private place, is considered as a leisure space for digitized leisure activities. Sleeping, having a rest or being with a partner seems to be substituted by scrolling the smartphone $[31,50]$. Consequent sleep deprivation has effects on sustained psychological well-being [29]. The use of mobile devices leads to idleness and perceived timelessness while staying physical immobile. Results of the content analysis and of the qualitative sentiment analysis show that smartphones have a marked agenda-setter function, along with the functions of separator and enabler. Mobiles as separators are a virtual presence in moments of rest physically separating two active day phases. According to our data, these moments connote a virtual switch off somewhat similar to the effect of drugs, with identified hints to the notions of self-reward, compulsion, and addiction in the sample. These results confirm and strengthen prior findings $[28,32,50]$. Mobile devices were also confirmed to equally serve as enablers with daily tasks and needs thereby actively empowering respondents and genuinely improving their quality of life. 
All in all, the aggregated role of smartphones in respondents' leisure and wellbeing has remained highly controversial.

The theoretical implications of our findings expand the academic knowledge on the aggregated role of smartphones in young adults' leisure time activities. Wider society can benefit from the research findings, stimulating young adults to acknowledge the aggregated roles and functions of their smartphones and to develop their digital well-being. Given that the relationship between the use of a smartphone and digital well-being does not develop in a vacuum, under laboratory conditions, potential environmental impacts should be considered when evaluating the results. A significant number of young adults live with their parents, so their feedback and value judgments about their child's lifestyle can influence the assessment of well-being. The investigated generation live as digital natives, their parents as digital immigrants, so the system of evaluation of leisure time is different from the examined point of view. The perceptions of well-being can be influenced by everyday conflicts.

\section{Limitations}

The findings of this study provide valuable insight into the content of diaries, but limitations must be noted. First, the chosen data collection method presents a limitation, that is, the division of the day to fifteen-minute intervals might influence the structure and content of the responses and introduce some kind of bias (e.g., activities lasting for a lot longer or, on the contrary, shorter than the fixed slot). Due to the nature of the diary-based approach, recall bias may also arise. Second, the use of a convenience sample is also noteworthy. Participants in the current study were primarily young university students in a very specific life-cycle situation. Third, only a selected number of respondents took part in our exploratory study. As a qualitative study, it focuses on each respondent's own and specific experiences, deals with their individual realities, and thus may not reflect a generalizable truth. Our study explored leisure-time activities and well-being experienced by university students during the COVID-19 pandemic, which may limit the generalizability of the findings. Future studies should implement mixed methods to explore the interconnections between digitized leisure, smartphone use, hybrid places and well-being.

Author Contributions: A.I., T.C., K.K. and G.M. equally contributed to research conceptualization. A.I., T.C., K.K. equally contributed to research design, data collection and writing. T.C. and K.K. contributed to methodology and data analysis, A.I. contributed to the theoretical background, writing and editing, and G.M. contributed to proofreading and editing. All authors have read and agreed to the published version of the manuscript.

Funding: This publication was supported by the TKP2020-NKA-02 project. Project no. TKP2020NKA-02 has been implemented with the support provided from the National Research, Development and Innovation Fund of Hungary, financed under the Tématerületi Kiválósági Program funding scheme.

Institutional Review Board Statement: The study was conducted according to the guidelines of the Declaration of Helsinki, and approved by the Ethics Committee of the Corvinus University of Budapest (Hungary) (protocol code KRH/103/2021 and 31 March 2021).

Informed Consent Statement: Informed consent was obtained from all subjects involved in the study.

Data Availability Statement: Not applicable.

Conflicts of Interest: The authors declare no conflict of interest. The funders had no role in the design of the study; in the collection, analyses, or interpretation of data; in the writing of the manuscript, or in the decision to publish the results.

\section{References}

1. Bae, S.M. The relationship between the type of smartphone use and smartphone dependence of Korean adolescents: National survey study. Child. Youth Serv. Rev. 2017, 81, 207-211. [CrossRef]

2. Park, S.; Yoon, H.; Koo, C.; Lee, W.S. Role of the Leisure Attributes of Shared Bicycles in Promoting Leisure Benefits and Quality of Life. Sustainability 2021, 13, 739. [CrossRef] 
3. Silk, M.; Millington, B.; Rich, E.; Bush, A. (Re-)thinking digital leisure. Leis. Stud. 2016, 35, 712-723. [CrossRef]

4. Ehrlén, V. Tracking oneself for others: Communal and self-motivational value of sharing exercise data online. Leis. Stud. 2021. [CrossRef]

5. Martínez-Sánchez, I.; Goig-Martínez, R.M.; Álvarez-Rodríguez, J.; Fernández-Cruz, M. Factors Contributing to Mobile Phone Dependence Amongst Young People-Educational Implications. Sustainability 2020, 12, 2554. [CrossRef]

6. Wang, P.; Chiu, D.; Ho, K.; Lo, P. Why read it on your mobile device? Change in reading habit of electronic magazines for university students. J. Acad. Librariansh. 2016, 42, 664-669. [CrossRef]

7. Nadolu, B.; Nadolu, D. Homo Interneticus-The Sociological Reality of Mobile Online Being. Sustainability 2020, 12, 1800. [CrossRef]

8. Wheatley, D.; Buglass, S.L. Social network engagement and subjective wellbeing: A life-course perspective. Br. J. Sociol. 2019, 70, 1971-1995. [CrossRef]

9. Siani, A.; Marley, S.A. Impact of the recreational use of virtual reality on physical and mental wellbeing during the Covid-19 lockdown. Health Technol. 2021, 11, 425-435. [CrossRef] [PubMed]

10. Derks, D.; Bakker, A.B. Smartphone use, work-home interference, and burnout: A diary study on the role of recovery. Appl. Psychol. 2012, 63, 411-440. [CrossRef]

11. Duke, É.; Montag, C. Smartphone addiction, daily interruptions and self-reported productivity. Addict. Behav. Rep. 2017, 6, 90-95. [CrossRef]

12. Han, J.S.; Patterson, I. An analysis of the influence that leisure experiences have on a person's mood state, health and wellbeing. Ann. Leis. Res. 2007, 10, 328-351. [CrossRef]

13. Herrschel, T.; Dierwechter, Y. Smart Transitions in City Regionalism. Territory, Politics and the Quest for Competitveness and Sustainability; Routledge: London, UK, 2018.

14. Kökény, L.; Kiss, K. There is a time and a place for everything (and for everyone): Examining main socio-demographic and territorial differences in use of leisure time. Reg. Stat. 2021, 11, 2. [CrossRef]

15. Vanden Abeele, M.M.P. Digital Wellbeing as a Dynamic Construct. Commun. Theory 2020, 1-24. [CrossRef]

16. Rotondi, V.; Stanca, L.; Tomasuolo, M. Connecting alone: Smartphone use, quality of social interactions and well-being. J. Econ. Psychol. 2017, 63, 17-26. [CrossRef]

17. Goggin, G. Ubiquitous apps: Politics of openness in global mobile cultures. Digit. Creat. 2011, 22, 148-159. [CrossRef]

18. Klopfer, E.; Squire, K. Environmental Detectives-The development of an augmented reality platform for environmental simulations. Educ. Technol. Res. Dev. 2008, 56, 203-228. [CrossRef]

19. Floros, C.; Cai, W.; McKenna, B.; Ajeeb, D. Imagine being off-the-grid: Millennials' perceptions of digital-free travel. J. Sustain. Tour. 2019, 29, 751-766. [CrossRef]

20. Farman, J. Mobile Interface Theory: Embodied Space and Locative Media; Routledge: New York, NY, USA, 2013.

21. Squire, K. Mobile media learning: Multiplicities of place. Horizon 2009, 17, 70-80. [CrossRef]

22. Squire, K.; Dikkers, S. Amplifications of learning: Use of mobile media devices among youth. Convergence 2012, 18, 445-464. [CrossRef]

23. de Souza e Silva, A. From cyber to hybrid: Mobile technologies as interfaces of hybrid spaces. Space Cult. 2006, 9, 261-278. [CrossRef]

24. Frith, J. Turning life into a game: Foursquare, gamification, and personal mobility. Mob. Media Commun. 2013, 1, 248-262. [CrossRef]

25. Xu, F.; Tian, F.; Buhalis, D.; Weber, J.; Zhang, H. Tourists as mobile gamers: Gamification for tourism marketing. J. Travel Tour. Mark. 2016, 33, 1124-1142. [CrossRef]

26. Goggin, G. Going Mobile. In The Handbook of Media Audiences; Nightingale, V., Ed.; Wiley-Blackwell: Malden, MA, USA, 2011; pp. 128-146.

27. Jain, M.J.; Mavani, K.J. A comprehensive study of worldwide selfie-related accidental mortality: A growing problem of the modern society. Int. J. Inj. Control. Saf. Promot. 2017, 24, 544-549. [CrossRef] [PubMed]

28. Kwon, M.; Lee, J.-Y.; Won, W.-Y.; Park, J.-W.; Min, J.-A.; Hahn, C.; Kim, D.-J. Development and validation of a Smartphone Addiction Scale (SAS). PLoS ONE 2013, 8, e56936. [CrossRef] [PubMed]

29. McDaniel, B.T.; Coyne, S.M. "Technoference": The interference of technology in couple relationships and implications for women's personal and relational well-being. Psychol. Pop. Media Cult. 2016, 5, 85-98. [CrossRef]

30. Anshari, M.; Almunawar, M.N.; Shahrill, M.; Wicaksono, D.K.; Huda, M. Smartphones usage in the classrooms: Learning aid or interference? Educ. Inf. Technol. 2017, 22, 3063-3079. [CrossRef]

31. Amichai-Hamburger, Y.; Etgar, S. Intimacy and smartphone multitasking-A new oxymoron? Psychol. Rep. 2016, 119, 826-838. [CrossRef]

32. Mellner, C. After-hours availability expectations, work-related smartphone use during leisure, and psychological detachment. Int J. Workplace Health Manag. 2016, 9, 146-164. [CrossRef]

33. Agger, B. iTime: Labor and life in a smartphone era. Time Soc. 2011, 20, 119-136. [CrossRef]

34. Sonnentag, S.; Binnewies, C.; Mojza, E.J. Staying well and engaged when demands are high: The role of psychological detachment. J. Appl. Psychol. 2010, 95, 965-976. [CrossRef] [PubMed]

35. Diener, E. Assessing subjective wellbeing: Progress and opportunities. Soc. Indic. Res. 1984, 31, 103-157. [CrossRef]

36. Veenhoven, R. Conditions of Happiness; Kluwer Academic: Dordrecht, The Netherlands, 1984; 434p. 
37. Cieslik, M. "Not Smiling but Frowning": Sociology and the "Problem of Happiness. " Sociology 2014, 49, 422-437. [CrossRef]

38. Dolan, P.; Peasgood, T.; White, M. Do we really know what makes us happy? A review of the economic literature on the factors associated with subjective wellbeing. J. Econ. Psychol. 2008, 29, 94-122. [CrossRef]

39. Gui, M.; Fasoli, M.; Carradore, R. "Digital Well-Being". Developing a New Theoretical Tool for Media Literacy Research. Ital. J. Sociol. Educ. 2017, 9, 155-173.

40. Verduyn, P.; Ybarra, O.; Résibois, M.; Jonides, J.; Kross, E. Do Social Network Sites Enhance or Undermine Subjective Well-Being? A Critical Review. Soc. Issues Policy Rev. 2017, 11, 274-302. [CrossRef]

41. Schwanen, T.; Wang, D. Well-Being, Context, and Everyday Activities in Space and Time. Ann. Assoc. Am. Geogr. 2014, 104, 833-851. [CrossRef]

42. Kjell, O.N.E. Sustainable Well-Being: A Potential Synergy Between Sustainability and Well-Being Research. Rev. Gen. Psychol. 2011, 15, 255-266. [CrossRef]

43. Ashforth, B.E.; Humprey, R.H. Emotion in the workplace: A reappraisal. Hum. Relat. 1995, 48, 97-124. [CrossRef]

44. Ryan, R.M.; Deci, E.L. On happiness and human potentials: A review of research on hedonic and eudaimonic well-being. Annu. Rev. Psychol. 2001, 52, 141-166. [CrossRef]

45. Bryman, A. Social Research Methods, 5th ed.; Oxford University Press: Oxford, UK, 2016; 743p.

46. Kahneman, D.; Krueger, A.B.; Schkade, D.A.; Schwarz, N.; Stone, A.A. A survey method for characterizing daily life experience: The day reconstruction method. Science 2004, 306, 1776-1780. [CrossRef] [PubMed]

47. Zimmerman, D.; Wieder, D. The diary: Diary interview method. Urban Life 1977, 5, 479-498. [CrossRef]

48. Babbie, E. Survey Research Methods; Belmont: Wadsworth, OH, USA, 1990.

49. Strauss, A.L.; Corbin, J. Basics of Qualitative Research: Grounded Theory Procedures and Techniques; Sage Publications: Newbury Park, CA, USA, 1990.

50. Lemola, S.; Perkinson-Gloor, N.; Brand, S. Adolescents' Electronic Media Use at Night, Sleep Disturbance, and Depressive Symptoms in the Smartphone Age. J. Youth Adolesc. 2015, 44, 405-418. [CrossRef] [PubMed]

51. Barnett, S. The Death of FOMO as We Knew It. Wired 2020, December 23. Available online: https://www.wired.com/story/ death-of-fomo/ (accessed on 20 February 2021). 